PRAMANA

(c) Indian Academy of Sciences

Vol. 82, No. 6

— journal of

June 2014

physics

p. 1119

\title{
Erratum to: Measurement of copper vapour laser-induced deformation of dielectric-coated mirror surface by Michelson interferometer
}

A WAHID*, S KUNDU, J S B SINGH, A K SINGH, A KHATTAR, S K MAURYA, J S DHUMAL and K DASGUPTA

Laser \& Plasma Technology Division, Beam Technology Development Group, Bhabha Atomic Research Centre, Mumbai 400 085, India

*Corresponding author. E-mail: awahid@barc.gov.in

DOI: 10.1007/s 12043-014-0733-6; $\boldsymbol{e P u b l i c a t i o n : ~} 22$ May 2014

The original publication of this article (DOI: 10.1007/s12043-014-0704-y) which appeared in Pramana - J. Phys. 82(2), 445 (2014), unfortunately contains an error. Figure 4 is not correct, and the correct figure is reproduced here in its entirety.

The authors apologize for this error.

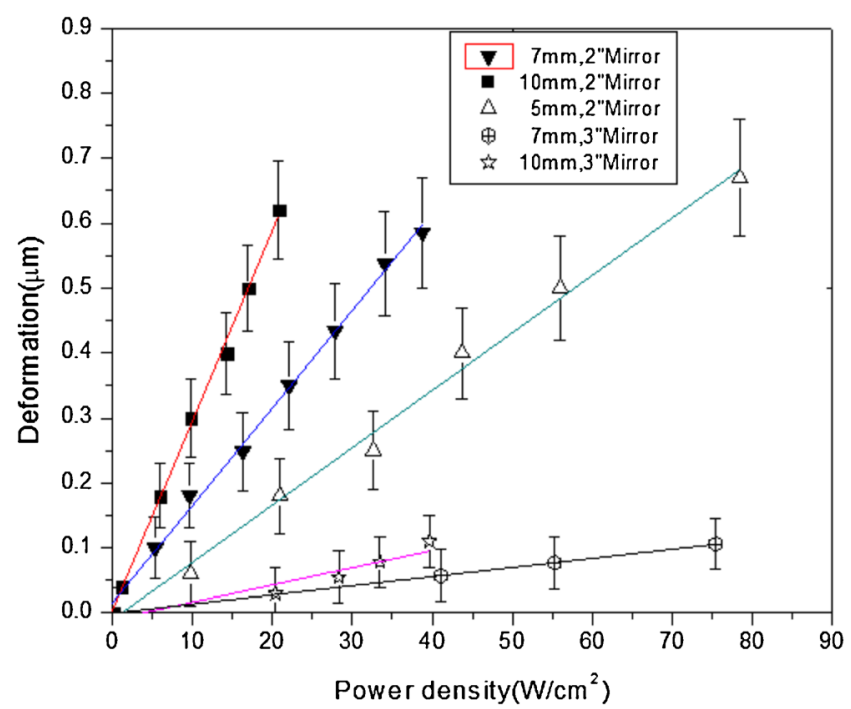

Figure 4. Deformation vs. average power density for mirrors with BK7 substrate. The inset data show spot size and mirror diameter. 